\title{
Chapter 16 \\ Challenges of Agricultural Land \\ Remediation and Renewal of Agriculture \\ in Iitate Village by a Collaboration \\ Between Researchers and a Non-profit \\ Organization
}

\author{
Masaru Mizoguchi
}

\begin{abstract}
We have tested several ways to revitalize agriculture in Fukushima by developing farmland decontamination methods that farmers can undertake by themselves. As a result, the rice harvested in a test field passed the official inspection of Fukushima Prefecture in 2014. Despite the efforts of local people, we have not yet succeeded to dispel the anxieties in the general public who believe that Fukushima's agricultural crops might contain radioactive cesium. Such "harmful rumors" are hampering the recovery of local agriculture in Fukushima. In this chapter, we review the challenges of agricultural land remediation and renewal of agriculture from a collaboration between researchers and a non-profit organization (NPO) and propose the scenario for the recovery of local agriculture and village life.
\end{abstract}

Keywords Agricultural land - Decontamination - Agricultural regeneration - Iitate Village $\cdot$ Radiation $\cdot$ Rural planning $\cdot$ Rural reconstruction scenario

\subsection{Introduction}

The accident at TEPCO's Fukushima Daiichi Nuclear Power Plant, which occurred in March 2011, became an unprecedented nuclear disaster. As a result, the forests, agricultural lands and oceans were contaminated extensively by radioactive cesium. In Iitate Village, Fukushima Prefecture, where the evacuation order was canceled in March 2017, decontamination work has been carried out using thousands of workers in preparation for the return of the Iitate Villagers in the spring of 2017.

M. Mizoguchi $(\bowtie)$

Graduate school of Agricultural and Life Sciences, The University of Tokyo, Tokyo, Japan

e-mail: amizo@mail.ecc.u-tokyo.ac.jp 


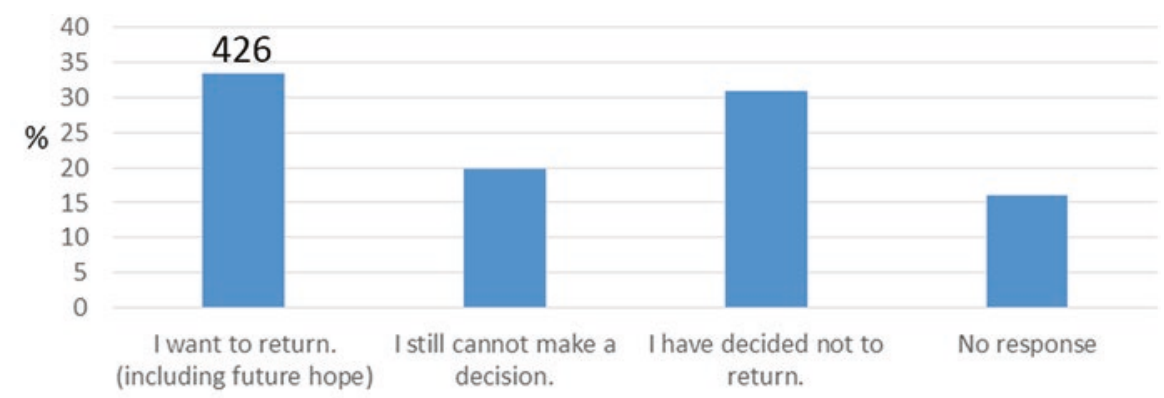

Intention to return to litate village

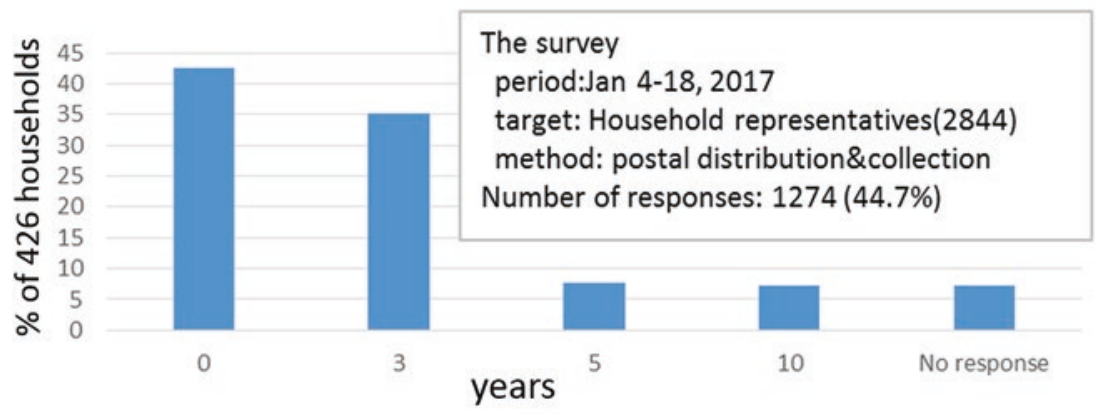

\section{Period to return after cancellation of evacuation order}

Fig. 16.1 Present situation as seen from the resident's intention survey (Iitate Village 2017) (Extracted from the Public Information "Iitate", issue 1, April 2017)

In January 2017, the reconstruction agency, Fukushima prefecture, and Iitate Village jointly conducted a questionnaire survey. Figure 16.1 presents some of the results from the survey (Iitate Village 2017). Among the 1271 households (44.7\% of the respondents), $33.5 \%$ of responding households said that "we want to return (including future hope)". Thirty-one percent replied "we have decided not to return", and $19.7 \%$ replied that they "still cannot judge". Of the 426 households who replied "they want to return", $42.5 \%$ said they want to return immediately, but many residents want to return in 3, 5 or 10 years. Moreover, 59.4\% said "Improvement in medical and nursing care welfare facilities" in the village is one of the conditions that needs to be met before returning. Two hundred and fifty-one households responded "I cannot judge yet". For these households, the conditions that need to be met before returning include: "When the infrastructure such as roads, buses, schools and hospitals will be restored (46.2\%)", "how many other residents are planning to return (45.4\%)", and "prospects for radiation dose reduction (44.2\%)". These results mean that many people intend to observe the situation for a while even though the evacuation order was canceled.

I entered Iitate Village 3 months after the nuclear accident and have tested several ways to revitalize agriculture with the collaboration of local farmers, NPO members and other researchers (Mizoguchi 2015a). In this chapter, I review the challenges of 
agricultural land remediation and the renewal of agriculture and propose the scenario for the recovery of local agriculture and village life.

\subsection{Collaboration Between Researchers and NPO}

Our activities are based on the collaboration of groups beyond the existing organizational framework (Kanno and Mizoguchi 2014; Yokokawa and Mizoguchi 2013).

\subsubsection{Authorized NPO "Resurrection of Fukushima" (Resurrection of Fukushima 2017)}

"Resurrection of Fukushima" was founded in June 2011 in Sasu district in Iitate Village, Fukushima Prefecture. As of the end of May 2017, there were 290 members and 6 groups of regular members. Senior members called "Ara Koki" (average age is about 70 years) are the core of the NPO. Volunteers with diverse backgrounds gather in Iitate Village every weekend and discuss various ways to help the recovery of Iitate Village based on the data acquired in collaboration with local farmers. More than 1000 volunteers participated each year in activities such as radiation measurement and analysis of radioactivity, development of decontamination technologies, and health care for the residents, etc. The latest discussion and data are uploaded promptly on the website (http://www.Fukushima-saisei.jp).

\subsubsection{Fukushima Reconstruction Agricultural Engineering Group (Fukushima Reconstruction Agricultural Engineering Meeting 2017)}

This is a group organized immediately after the nuclear accident by agricultural engineering researchers who are specialists of agricultural land, irrigation, soil physics, hydrology, and agro-informatics in the Graduate School of Agriculture and Life Sciences (GSALS), The University of Tokyo. The group which is a group member of the NPO "Resurrection of Fukushima" plays an important role carrying out field and soil surveys.

\subsubsection{Campus Group "Madei”}

In September 2012, the mayor of Iitate Village and the Dean of GSALS exchanged a letter of research cooperation between Iitate Village and GSALS. Based on the letter, a volunteer group was organized by employees of GSALS, who want to 
support the activities of the NPO without going to Iitate Village. The group is named "Madei" which is a dialect of Iitate Village meaning "politely". Members of the group meet after work every Tuesday, and pack samples, such as soil and plants collected by the NPO members in Iitate Village on weekends, into vial tubes, then send the tubes to a researcher at the Radioisotope facility (RI facility) on campus.

\subsubsection{Rehabilitation Support Project (University of Tokyo Agricultural Life Science Graduate School of Grants- in-Aids Rehabilitation Support Project 2017) of the Graduate School of Agriculture and Life Sciences (GSALS), The University of Tokyo}

This is a project which was initiated by the Dean of the GSALS immediately after the earthquake. Numerous researchers are involved in field surveys and reconstruction assistance in various forms. Under the project, measurement of the radioactive cesium concentration of samples collected in litate Village is carried out at the Radioisotope facility. This project regularly holds "Research report meetings on the influence of radioactivity on agricultural and livestock products, etc." The meeting has been held 13 times as of January 2017.

\subsection{Development of Agricultural Land Decontamination Method by Farmers Themselves (Mizoguchi 2013)}

A technical document for agricultural land decontamination (Ministry of Agriculture, Forestry and Fisheries 2013) (MAFF; Ministry of Agriculture, Forestry and Fisheries, 2013) recommends three decontamination methods according to the level of farmland contamination. They are (1) the topsoil stripping-off method $(>10,000 \mathrm{~Bq} / \mathrm{kg}$ soil), (2) the muddy water method ( $>5000 \mathrm{~Bq} / \mathrm{kg}$ soil), and (3) reverse cultivation method ( $<5000 \mathrm{~Bq} / \mathrm{kg}$ soil). However, only the topsoil stripping-off method has been used in the field, which has resulted in the contaminated soil being stored in black container bags; these bags are currently being stored on agricultural land that is easily accessible (Resurrection of Fukushima 2017). These storage places are referred to as a "temporary-temporary storage place" because a temporary/final storage place has still not been determined by the government (Photo 16.1).

We focused on the property that cesium is fixed onto clay particles. Based on the idea that "the decontamination of agricultural land is equivalent to the removal of clay particles", we developed several agricultural land decontamination methods that farmers themselves can easily practice (Mizoguchi 2014a), which are different from the methods proposed by MAFF. 


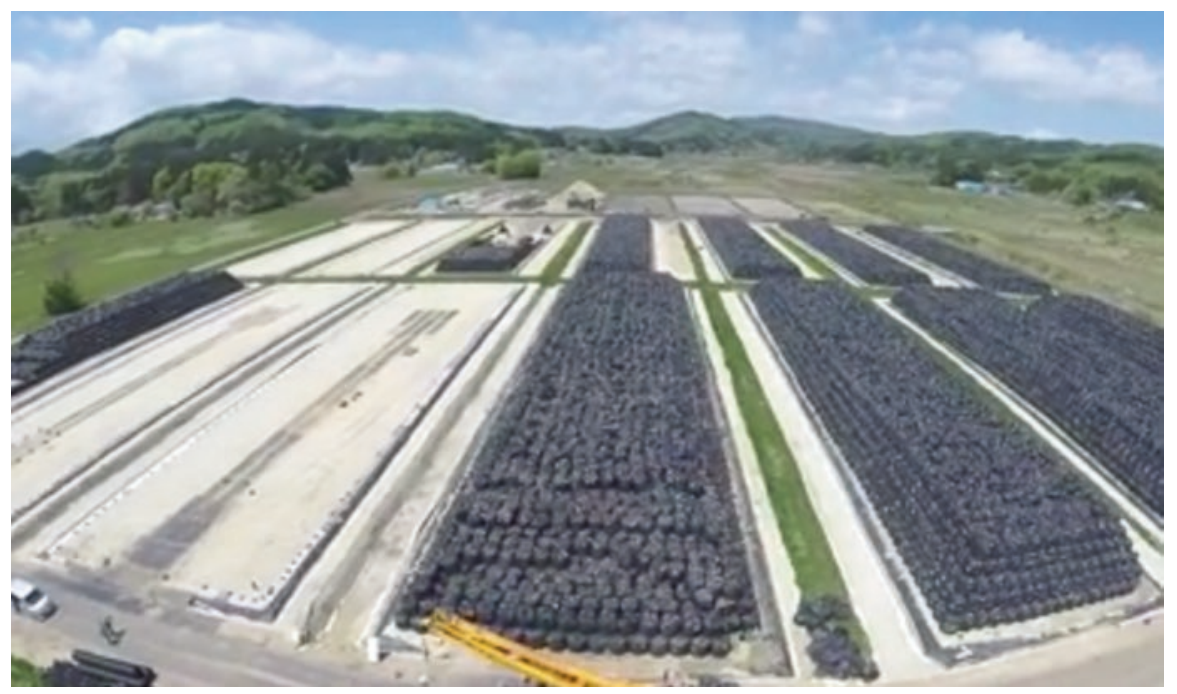

Photo 16.1 Contaminated soil bags piled up in a temporary-temporary storage place (Resurrection of Fukushima 2017). (Photo and video provided: NPO Resurrection of Fukushima)

\subsubsection{Muddy Water Flushing Out Method with a Hand Weed Machine}

In April 2012, we conducted an experiment at a paddy field in Sasu district in Iitate Village, Fukushima Prefecture. We irrigated water into a $5 \mathrm{~m} \times 10 \mathrm{~m}$ paddy field and mixed the surface soil of the paddy field with a hand weed machine (this machine was often used after rice planting more than 50 years ago). Next, a tennis court brush was used to flush out the muddy water containing radioactive cesium. Using this method, it was found that $80 \%$ of radioactive cesium can be removed.

With this method, muddy water was flushed out into a $1 \mathrm{~m}$-deep drainage channel which was dug around the paddy field. After 3 months, the muddy water which was removed from the paddy field penetrated underground, and only dry clay remained on the bottom of the drainage channel. We measured radioactive cesium concentration in this dry clay and found that radioactive cesium remained in the soil layer to a depth of 6-7 cm from the bottom of the drainage channel (Mizoguchi 2013a). This is because the clay particles which contain radioactive cesium were trapped in the soil pores by the soil filtration function (Yahata 1980). To explain this principle, we video recorded a simple experiment using a plastic bottle and uploaded it to YouTube as teaching material for the public (Kato et al. 2016). 


\subsubsection{Muddy Water Flushing Out Method with a Tractor (Mizoguchi 2014b)}

The muddy water flushing out method with a hand weed machine cannot be used for the decontamination of a large area. In addition, paddy fields have been abandoned without cultivation for 6 years. Therefore, grasses and shrubs extend roots into the soil, and wild boars have been digging the ground surface in some paddy fields. As a result, the radioactive cesium accumulated in the surface layer has been mixed. In May 2013, we tested another method using a tractor at a paddy field in Komiya district in Iitate Village, Fukushima Prefecture. We mixed soil with water in the paddy field using a tractor and flushed out the muddy water into a moat that was dug at a corner of the paddy field (Photo 16.2).

The muddy water flushing out method using either the hand weed machine or tractor corresponded to Method 2 in the MAFF manual (Ministry of Agriculture, Forestry and Fisheries 2013). With both our methods, the settling time of clay particles in water is important to collect clay particles efficiently. Also, as muddy water penetrates into the bottom of the moat, clay particles must be trapped in the soil pores. However, radioactive cesium might be adsorbed to organic matter which sometimes forms a colloid. In that case, there is a possibility that the settling velocity of the particles and the trapping rate of the particles in the soil pores may change. Therefore, we need to elucidate the phenomena of colloid migration and clogging in the soil.

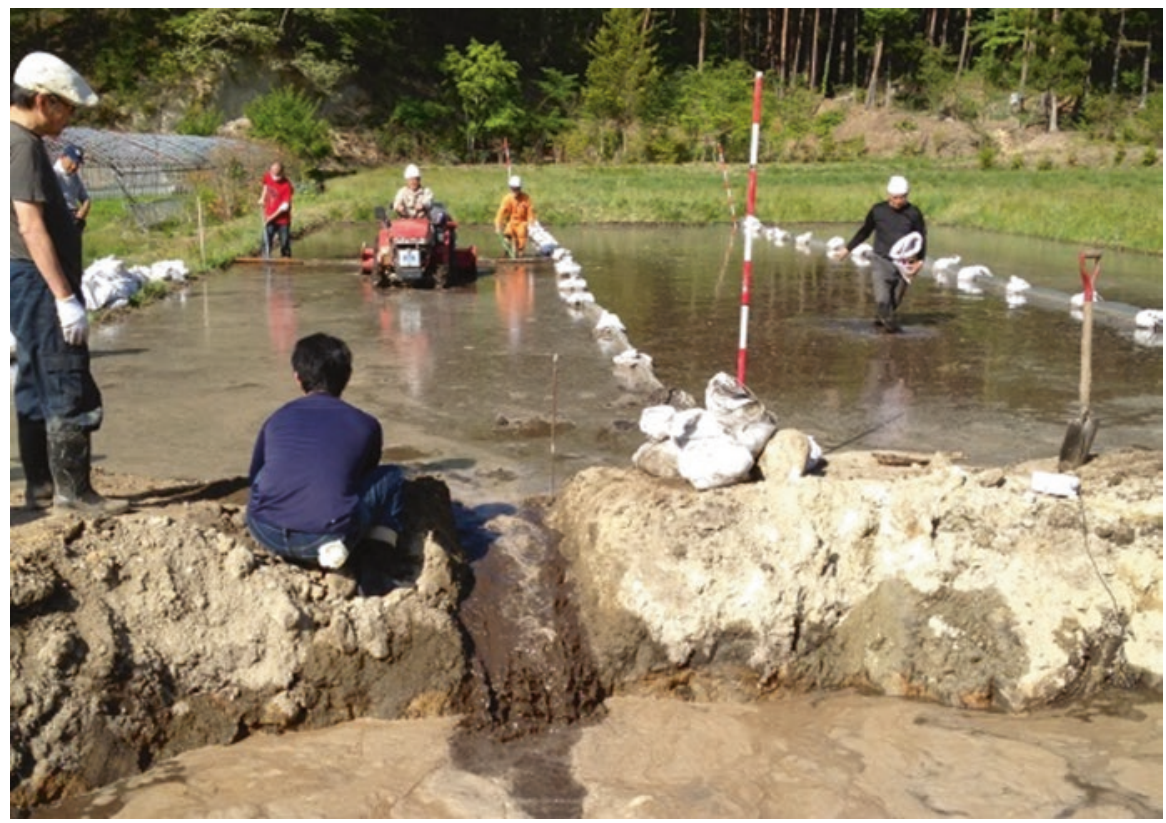

Photo 16.2 Decontamination of farmland by muddy water flushing out method with a tractor 


\subsubsection{Burial Method of Contaminated Soil-Madei Method (Mizoguchi et al. 2013)}

According to a previous study (Miyazaki 2012), if contaminated soil is covered over with a $50 \mathrm{~cm}$ layer of non-contaminated soil, the radiation dose can be attenuated from 1/100 to 1/1000. In December 2012, we conducted an in-situ burial experiment of contaminated soil at a paddy field in Sasu district in Iitate Village, Fukushima Prefecture. We stripped $5 \mathrm{~cm}$ of contaminated topsoil from a paddy field $(10 \mathrm{~m} \times 30 \mathrm{~m})$, and dug a trench $(2 \mathrm{~m}$ wide, $30 \mathrm{~m}$ long, $1 \mathrm{~m}$ deep) in the center of the paddy field. Then, we buried the contaminated soil at a depth of $50-80 \mathrm{~cm}$ in the trench and covered the trench with non-contaminated soil to a depth of $50 \mathrm{~cm}$ above the contaminated soil (Mizoguchi et al. 2013; Photo 16.3).

This method is a combination of Method 1 and 2 in the MAFF manual. We named this method "Madei construction method".

We continued the cultivation test of rice in this paddy field, and confirmed (Ii et al. 2015) that the radioactive cesium concentration of brown rice was below the Japanese standard value of $100 \mathrm{~Bq} / \mathrm{kg}$. However, since this method is not an approved decontamination method in Japan, the local government requested us to bury the rice harvested in 2012 and 2013 under the ground. However, after tenacious negotiations between the NPO and the local government, the brown rice harvested in 2014 was permitted to receive the official inspection under the management

Photo 16.3 Burial method of contaminated soil

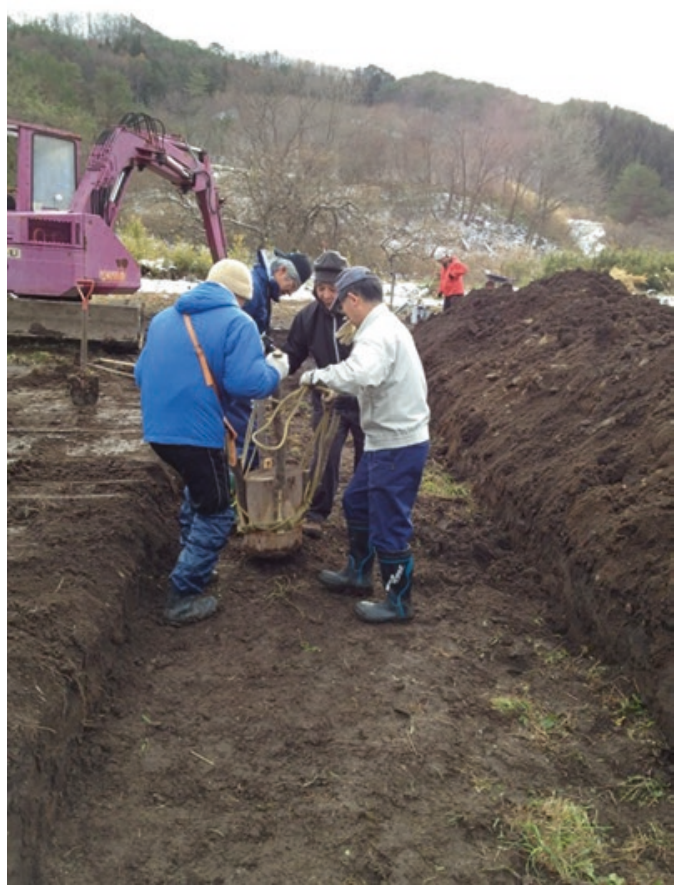


of the prefectural government and succeeded to pass the inspection. In this way, it was proved that safe rice can be produced by our own decontamination method.

\subsubsection{Monitoring of Buried Contaminated Soil (Mizoguchi et al. 2015)}

Although we proved the safety of rice production in the paddy field decontaminated by the Madei construction method, we also needed to prove that radioactive cesium cannot leak out from the buried contaminated soil. Therefore, we set an observation well using a PVC pipe in a paddy field where contaminated soil was buried under the ground, and periodically measured the soil radiation dose by inserting a radiometer into the well. Figure 16.2 shows the soil radiation dose (cpm) measured by a new 10-unit Geiger-Müller tube radiometer that we developed. Solid lines are

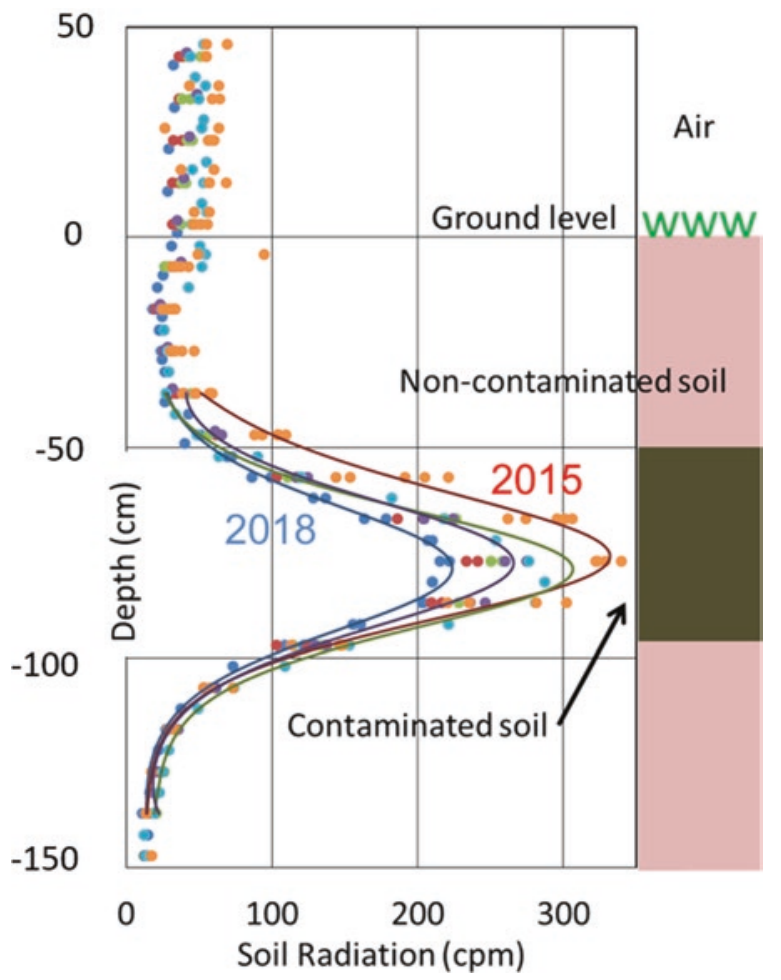

Fig. 16.2 Profiles of radiation dose in the soil. All data measured every 6 months from March 2015 are plotted. Solid lines are fitting curves of the data measured in March 2015, 2016, 2017 and 2018. The Cs-contaminated soil was buried to a depth of about 50-90 cm under the ground 
fitting curves of data measured in March 2015, 2016, 2017 and 2018. The radiation dose showed a normal distribution shape with a peak at a depth of about $70 \mathrm{~cm}$. This is because the radiation from the contaminated soil buried in $50-90 \mathrm{~cm}$ is attenuated in the soil.

We need to continue monitoring buried contaminated soil over the long-term. On the other hand, a study which predicts long-term cesium migration in the soil using a simulation model is needed because it is difficult to directly demonstrate that radioactive cesium does not move.

\subsubsection{Environmental Monitoring in the Iitate Village (Mizoguchi 2013b)}

Environmental monitoring of the radiation level in the village is important to evaluate the decontamination effect and to judge when the villagers should return to the village. In particular, it is important to accumulate scientific data such as the relationship between wind direction/wind speed and radiation dose, the relationship between precipitation intensity and the amount of outflow/turbidity of rivers. Based on those data, we must discuss the villagers' lifestyle and agricultural revitalization after returning to the village. We added a radiation meter to our field monitoring system (Mizoguchi and Ito 2015) (FMS) that we developed in our laboratory, and have been conducting environmental monitoring at several points, such as paddy fields, forests and houses, in Iitate Village since October 2011. Some meteorological sensors and monitoring equipment that we use here were donated to the Japanese Society of Irrigation, Drainage and Reclamation Engineering (JSIDRE) by sensor/ equipment developers after the 2011 earthquake.

Figure 16.3 is an example of weather and radiation dose data. Because the normal radiation sensor was expensive and difficult to obtain after the nuclear power plant accident, we measured radiation dose using a cheap photodiode-semiconductor sensor at the garden of a residence in Iitate Village. Therefore, the sensor sometimes picked up noise and the data were unstable. However, since the radiation dose was observed automatically at the fixed point, it was effective to see the trend of the change of radiation. By comparing with the on-site image data, we found that the radiation dose decreases due to snow cover (Fig. 16.4). In addition, we found a tendency that the radiation dose will rise on dry and fine days. Currently, the price of the radiation sensor has decreased, so we have upgraded to a more accurate and stable sensor and are continuing to observe the radiation dose at the same site. We also developed a portable device (Suzuki et al. 2015) that measures soil radiation in cooperation with radiation measurement engineers that we became acquainted with after the accident. These devices are now used by villagers to inspect their own farmland by themselves. 


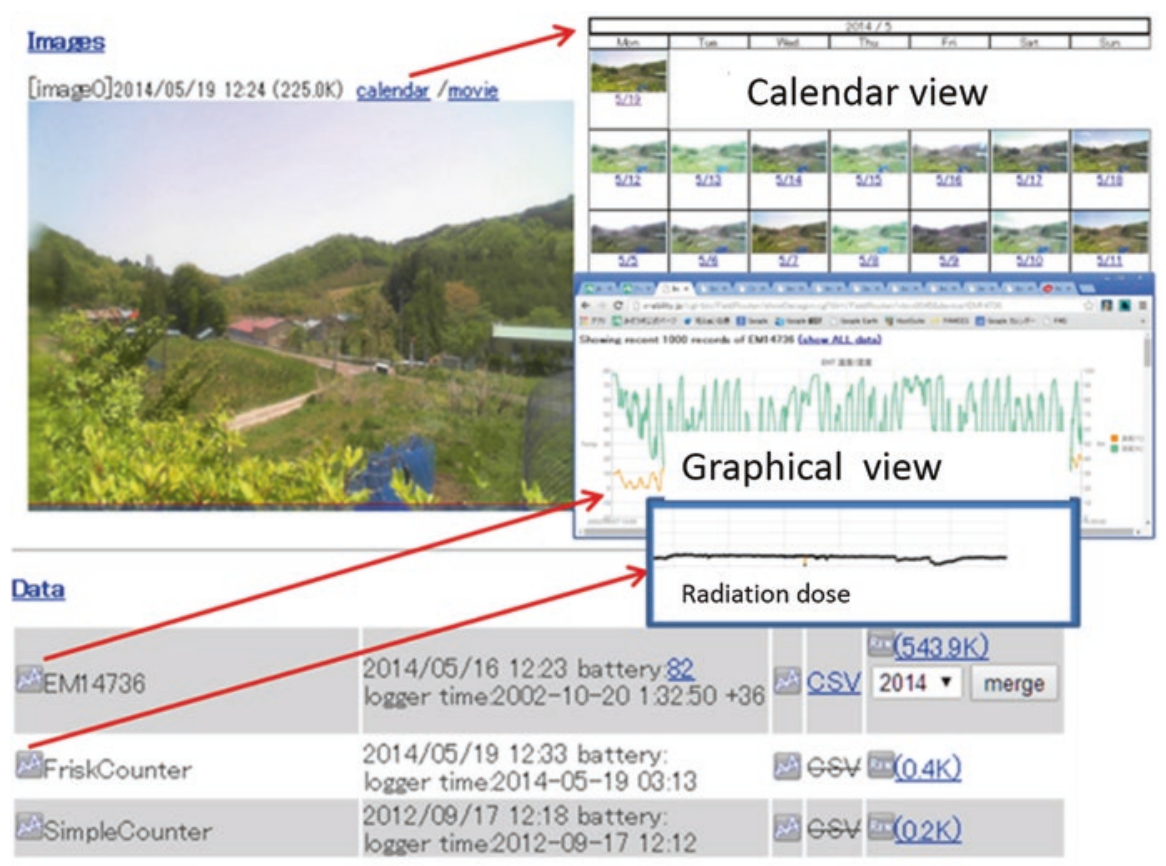

Fig. 16.3 Environment monitoring in litate Village using the field monitoring system (FMS). Data such as radiation dose, air temperature, humidity, precipitation, wind direction/wind speed, solar radiation, etc. are automatically transmitted to the cloud server together with the image data every day

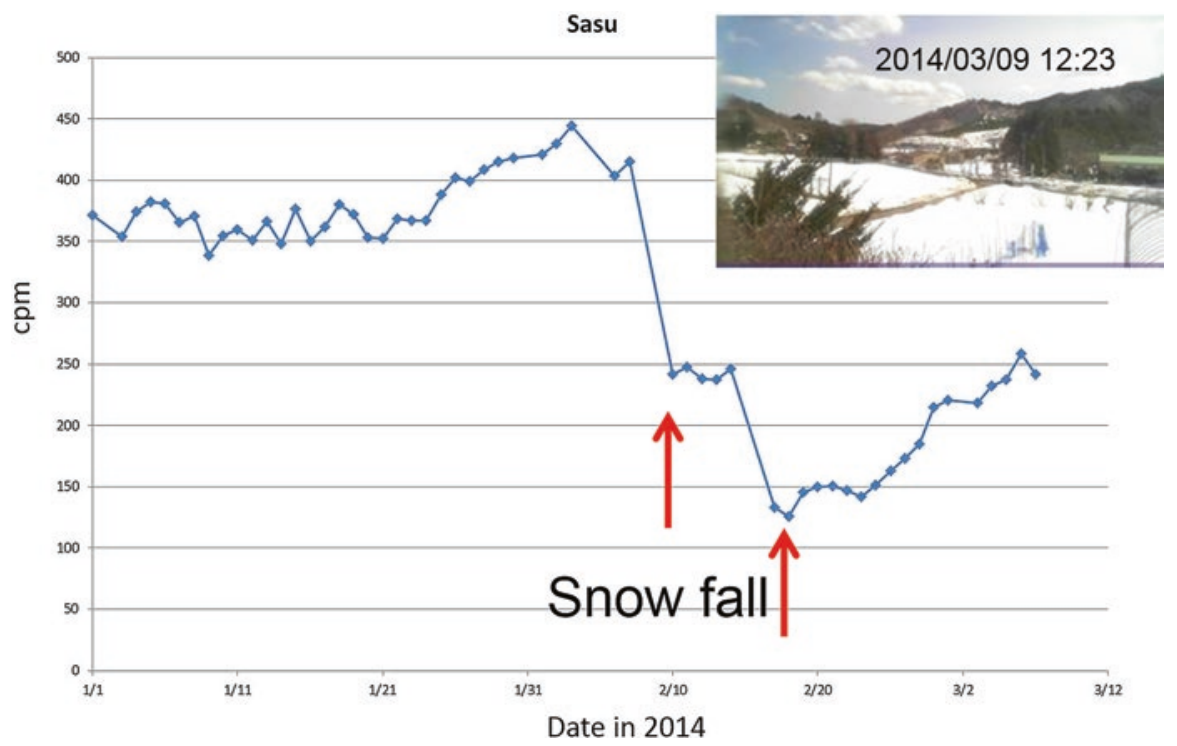

Fig. 16.4 Effect of radiation shielding by snow 


\subsection{The Current Status of Agricultural Land After Decontamination}

After decontamination work, to decrease the radiation dose in the environment the topsoil in paddy fields in Iitate Village was replaced with mountain soil which is not fertile (Photo 16.4).

In 2015, we conducted a survey of paddy fields (Mizoguchi 2017) with regards to (1) radioactive cesium concentration in agricultural soil, (2) the thickness of the covered soil, (3) soil hardness, and (4) drainage characteristics of the soil. The following were our findings:

(1) The degree of decontamination varied depending on the location, even in the same paddy field.

(2) The levee of the paddy field was not decontaminated.

(3) The thickness of the covered soil is not necessarily uniform.

(4) In the paddy field after decontamination, a hard layer was formed at the boundary $(5-10 \mathrm{~cm})$ between the covered soil and the original paddy soil in addition to the conventional tiller layer $(20-30 \mathrm{~cm})$.

(5) Due to poor drainage, many paddy fields become flooded after heavy rain. The poor drainage is due to a hard layer formed by a heavy machinery used for decontamination work. Agricultural land regeneration based on these findings is an important mission for agricultural engineers.

Photo 16.4 Soil survey after decontamination work. The topsoil in paddy fields in Iitate Village was replaced with mountain soil

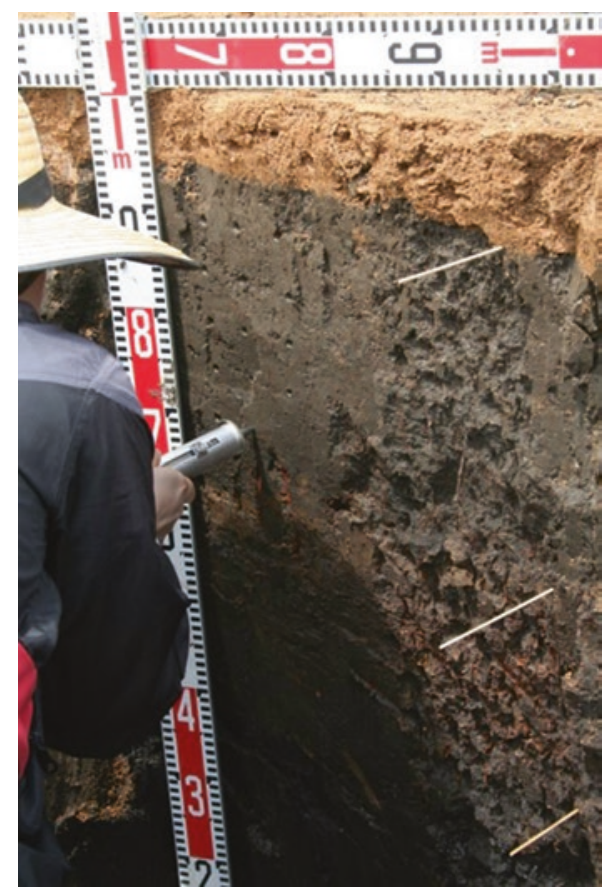




\subsection{Rural Reconstruction Scenario}

\subsubsection{Creation of a New Japanese Agriculture Model (Mizoguchi 2015b)}

In the past, the ordered beautiful paddy fields in Japan were constructed by public land improvement projects. Immediately after the land improvement, soil fertility was normally low. Therefore, high crop yields were not expected for the first few years after construction. Perhaps, farmland in Fukushima after decontamination will recover after several years. In other words, we must continue to improve the soil for several years considering the usage of the farmland.

The biggest problem is to keep farmers motivated to continue agriculture in spite of the hard conditions. The future of agriculture in Japan is uncertain, not only in Fukushima. There is also the damaging rumours about the safety of agricultural products of Fukushima. However, hard times bring opportunity! We will be able to use Fukushima's world-famous name to sell Fukushima's agricultural and livestock products to the world. Through discussions among all stakeholders, we need to develop novel schemes to encourage companies and new farmers to come to Fukushima. Moreover, we can control the environment inside the greenhouses and cultivate flowers and vegetables while using state-of-the-art ICT technology. And, we need to think positively that we can create a new Japanese agriculture model whose products will be internationally competitive.

\subsubsection{Human Resource Development}

The important point in thinking about regional reconstruction after the nuclear accident is to nurture young people who overcome Fukushima's handicap. We sometimes take students on field trips to Iitate Village. In a class lecture (Mizoguchi 2017) back on campus, we talk to the students about the mission of researchers to solve on-site problems in Iitate Village. After visiting the Iitate Village, the student's opinions changed greatly.

In January 2016, a student-organized agricultural food exhibition was held at the Faculty of Agriculture, the University of Tokyo. A graduate student whose hometown is Iitate Village planned tasting sales with young people of the same generation with the aim to promote the recovery of Iitate beef. In addition, female college students in Yokohama also developed a cake using vegetables test-cultivated in Iitate Village as an attempt by Community Supported Agriculture (CSA) to connect producers and consumers. In this way, the young generation is also interested in rural reconstruction. The university needs to to develop human resources among the young who can draw a scenario of rural reconstruction from a comprehensive perspective and work on problem-solving with local people. 


\subsection{Conclusion}

In this chapter, I reviewed the challenges of agricultural land remediation and the renewal of agriculture that I conducted with the collaboration of local farmers, NPO members and researchers since I entered Iitate Village immediately after the nuclear accident. In addition, I proposed some of my own ideas regarding rural reconstruction.

I believe we have done almost all that we can to decontaminate the agricultural land affected by radioactive cesium fallout. However, we often heard from evacuated villagers that "What we are most sorry is that the family gathering place is gone". From the viewpoint of rural planning by a sociological approach, we need to still consider more ways to revive village life.

Acknowledgments I would like to thank the NPO members (President: Mr. Yoichi Tao) for their collaboration, and the local farmers (Mr. Muneo Kanno, Mr. Kinichi Okubo, Mr. Takeshi Yamada, Mr. Keiichi Kanno) who provided us land in Iitate Village for the past 7 years to carry out our field experiments.

\section{References}

Fukushima Reconstruction Agricultural Engineering Meeting. Tackling agricultural restoration from decontamination of agricultural land - the way to realistic decontamination technology development utilizing the research of "Agricultural Engineering". http://utf.u-tokyo. ac.jp/2013/07/post-43c5.html (As of April 2017)

Ii I, Tanoi K, Uno Y, Nobori T, Hirose A, Kobayashi N, Nihei N, Ogawa T, Tao Y, Kanno M, Nishiwaki J, Mizoguchi M (2015) Radioactive Caesium concentration of lowland rice grown in the decontaminated paddy fields in Iitate village in Fukushima. Radioisotopes 64(5):299-310

Iitate Village. Public information "Iitate", issue 1, April (2017)

Kanno M, Mizoguchi M (2014) Soil decontamination in Iitate by cooperation of village, NPO and academic. Trends Sci 19(7):36-39

Kato C, Sakai M, Nishiwaki J, Tokumoto I, Hirozumi T, Watanabe K, Shiozawa N, Mizoguchi M (2016) Classes on reconstruction agriculture at elementary school in Fukushima Prefecture. Water Land Environ Eng 84(6):15-18

Ministry of Agriculture, Forestry and Fisheries (2013) Technical document on measures against decontamination of agricultural land, February 2013

Tsuyoshi Miyazaki (2012) Attenuation effect of cesium radiation by soil, toward recovery of agriculture, forestry and fishery industry from eastern Japan great earthquake disaster - technical recognition for damage recognition and understanding, reconstruction-, Association of Japanese Agricultural Scientific Society, 21. http://www.ajass.jp/pdf/recom2012.1.13.pdf (As of April 2017)

Mizoguchi M (2013a) Remediation of Paddy soil contaminated by Radiocesium in Iitate Village in Fukushima prefecture. In: Agricultural implications of the Fukushima nuclear. Springer, Tokyo, pp 131-142

Mizoguchi M (2013b) Soil decontamination and radiation monitoring. J Soc Instrum Control Eng 52(8):730-735

Mizoguchi M (2013) Development of agricultural land decontamination method that can be done by farmers themselves, soil science of radiation decontamination - from forests, fields, fields to home garden, Scientific meeting series 20. Japan Science Support Foundation, pp 135-151 
Mizoguchi M (2014a) Agricultural restoration by soil physicists - agricultural land decontamination for farmers by farmers, Columbus (March issue), pp 22-24

Mizoguchi M (2014b) Radioactive matter problem - what should soil physics do? J Jpn Soc Soil Phys 126:3-11

Mizoguchi M (2015a) The farmer's spirit will want to decontaminate his own farmland by himself, how to act after the nuclear accident - the trajectory of experts and victims, the University of Tokyo Hospital, pp 45-61

Mizoguchi M (2015b) Finding the possibility of Japanese style agriculture in Iitate Village by agricultural engineering for reconstruction, Columbus (May issue), pp 20-22

Mizoguchi M (2017) Current status and issues of radioactive contamination in Fukushima. J Jpn Soc Soil Phys 135:5-7

Mizoguchi M. Lectures related to Iitate Village, http://www.iai.ga.a.u-tokyo.ac.jp/mizo/edrp/fukushima/Iitate-lec14.html (As of April 2017)

Mizoguchi M, Ito T (2015) Field monitoring technology to change agriculture rural. Water Land Environ Eng 83(2):3-6

Mizoguchi M, Ito T, Tao Y (2013) Burial experiment of soil contaminated by radiocesium at a paddy field in Iidate Village, Fukushima Prefecture. Abstracts of Water, Land and Environmental Engineering meeting

Mizoguchi M, Itakura Y, Kanno M, Tao Y (2015) Radiation measurement in paddy soil layer that was buried contaminated topsoil. Abstracts of Water, Land and Environmental Engineering meeting

Resurrection of Fukushima. http://www.fukushima-saisei.jp (As of April 2017)

Resurrection of Fukushima: Reality of provisional casual storage place. https://www.facebook. com/FukushimaSaisei/videos/1054291244592879/ (As of April 2017)

Suzuki S, Itakura Y, Mizoguchi M (2015) Development and application of the device for measuring the vertical distribution of radiocaesium concentration in soil. Abstracts of Water, Land and Environmental Engineering meeting

University of Tokyo Agricultural Life Science Graduate School of Grants-in-Aids Rehabilitation Support Project. http://www.a.u-tokyo.ac.jp/rpjt/ (As of April 2017)

Yahata T (1980) Matters related to filtration function. Physics of soil (3rd press), The University of Tokyo Press, Tokyo, pp 142-156

Yokokawa H, Mizoguchi M (2013) Collaboration structure aimed at resurrection of Iitate Village. Phys Properties Soil 125:53-54

Open Access This chapter is licensed under the terms of the Creative Commons Attribution 4.0 International License (http://creativecommons.org/licenses/by/4.0/), which permits use, sharing, adaptation, distribution and reproduction in any medium or format, as long as you give appropriate credit to the original author(s) and the source, provide a link to the Creative Commons license and indicate if changes were made.

The images or other third party material in this chapter are included in the chapter's Creative Commons license, unless indicated otherwise in a credit line to the material. If material is not included in the chapter's Creative Commons license and your intended use is not permitted by statutory regulation or exceeds the permitted use, you will need to obtain permission directly from the copyright holder.

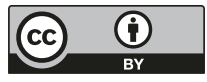

